\title{
Tectonic and Seismotectonics Survey in Behbahan
}

\author{
S. Y. Zolfegharifar ${ }^{1,2}$, M. Bosak ${ }^{1}$ \\ ${ }^{1}$ Department of Civil Engineering, Yasooj Branch, Islamic Azad University, Yasooj, Iran \\ ${ }^{2}$ Department of Geotechnics \& Transportation, Faculty of Civil Engineering, Universiti Teknologi Malaysia, \\ Johor Bahru, Malaysia \\ Email: syzoalfeghary@gmail.com
}

Received 11 January 2016; accepted 21 February 2016; published 25 February 2016

Copyright (C) 2016 by authors and Scientific Research Publishing Inc.

This work is licensed under the Creative Commons Attribution International License (CC BY). http://creativecommons.org/licenses/by/4.0/

(c) $\underset{\mathrm{EY}}{\mathrm{O}}$ Open Access

\begin{abstract}
Among the natural hazards, destructive earthquakes are the most common cause of casualties and financial losses and human deaths several times more in developing countries than developed countries. By increasing urbanization and construction process, construction activities and because Behbahan is a new city and is located near active faults, earthquake risk is increasing and will have disastrous results. Historical data also indicate destructive earthquakes in 1052 and 1085 with the magnitudes of 8.6 and 8.5 on the Richter scale which destroyed Arjan and killed many people. Due to frequent earthquakes in Behbahan as well as numerous small and large faults around it, the city has high seismic potential. So locating new developments and constructions should be more accurate.
\end{abstract}

\section{Keywords}

Seismotectonics, Zagros, Fault, Arjan, Behbahan

\section{Introduction}

Destructive earthquakes have occurred in Zagros zone and have usually associated with financial losses and many casualties. Many of these earthquakes have occurred in southern Zagros, especially in areas with more gentle folds. Despite intense seismic activity in southern Zagros, destructive earthquake occurrence is rare. Earthquakes such as Ghir (10 April 1972), Khoorgu, Bandar-E Abbas (11 March 1977) and Naghan (22 April 1977) with the magnitudes of 7, 9.6 and 6 degrees on the Richter scale, respectively, are destructive earthquakes in southern Zagros in the present century [1] and without creating ground faults, they indicate resurgence of peripheral activity of deep faults in the Precambrian basement of the zone, which indicates the link between earth- 
quakes and underlying structures.

Behbahan is located near the mountain front fault that its movements have caused massive earthquakes. Therefore, Behbahan is considered as one of the high-risk seismic zones of Khuzestan province and the country. Behbahan is located near major faults such as Behbahan, Arjan and Aghajari faults that movement of each one will cause destructive earthquakes. During the past thirty-five years more than 42 earthquakes with the magnitudes over 4 on the Richter scale have occurred in Behbahan [2].

\subsection{General Characteristics of Behbahan}

Behbahan is located in the southeastern part of Khuzestan province between 49 degrees 47 minutes and 50 degrees 33 minutes East of Greenwich meridian and 30 degrees 10 minutes and 30 degrees 56 minutes North of the equator. Behbahan is a foothill area and its height from sea level is equal to 300 meters. So far, the city population is estimated as 120,000 people. Behbahan is located $200 \mathrm{~km}$ far from Ahvaz, the provincial capital, and $1180 \mathrm{~km}$ far from Tehran, the capital.

\subsection{General Geology of the Area}

In general, Khuzestan is composed of mountainous and plains, mostly mountainous formations are associated with the third period, and the plains are associated with Quaternary or the fourth period. In Khuzestan plains which starts from Folded Zagros mountains and ends to the south of Persian Gulf sediments are coarse-grained at first and gradually are replaced by fine-grained sediments so that in the south of the province sediments are entirely fine-grained. These sediments are the results of activities of Karun, Dez, Karkheh, Jarrahi rivers and other surface flows and mainly consist of clay, silt, sand and sometimes gravel and gypsum nodules and are extended in the forms of hills, alluvial and fluvial terraces [3]. Behbahan is mainly located on non-consolidated sediments of the fourth period (Quaternary). These sediments are located on Bakhtiari conglomerate and Lahbari marls of Aghajari formation and are the results of the weathering of these two formations. The case study is tectonically located in fold-thrust Zagros structural zone and is influenced by the characteristics of this zone. Behbahan consists of mountainous and plains. Generally, it is located in the southern-southwestern part of Zagros mountain range and its foothills. Khaeez and Talrish are two important and high mountains in the north of Behbahan which are extended from west to east. From the north to the south, the height of mountains and hills is reduced and in Aghajari zone (Omidieh) we enter into the Khuzestan flat plain. Small and large plains are scattered among the mountains and hills and Behbahan is the largest plain. Khaeez mountain (1536 m elevation) is the highest mountain of Behbahan. The major formations beyond the project area are mainly Cretaceous and younger sedimentary series which are as follows: Bakhtiari Conglomerate Formation, Lahbari section, Gachsaran Formation, upper Fars or Aghajari Formation, Middle Fars or Mishan Formation, Lower Fars or Gachsaran, Asmari, Formation, Pabdeh Formation and Gurpi Formation.

\subsection{Seismicity of Iran and Zagros}

In the global context, the Iranian plateau is located at the collision of Saudi Arabia (Saudi Arabia-Africa), India (India-Australia) and Eurasia (Europe-Asia) plates. The collision of these plates has caused that the Iranian plateau crust which is weaker than mentioned plates is distorted and surrounded by folds and mountains such as Zagros in the West, Alborz and Kopet Dagh mountains in the North and North East and mountains in Eastern of Iran and Makran in the East and Southeast, respectively. Mountains and folds of Iranian plateau are not yet sustainable, so with plates' movements we can see the continuation of seismic activities in most parts of Iran, especially in mountain areas. In Zagros zone, which is actually the collision zone of the Arabian plate with Iran [1], forces are compressive. Ductile evaporate layers such as Hormuz salts in the zone has caused that earthquakes often show short return period and as a result, due to the short time interval between earthquakes, the accumulated energy is not enough to cause earthquakes with high magnitudes. So Zagros often has frequented earthquakes with medium magnitude which are mostly caused by a few evaporate formations without surface fracture. Zagros is one of the most active seismic zones in Iran. Dividing Zagros tectonic zone into smaller parts apparently seems to be complicated because the mechanism of its earthquakes is still not sufficiently known, but it is mainly divided into two zones, East and West. Seismicity of this zone is formed as a result of detected movements which are on one hand due to the movement of north-northeast part of the Arabian plate towards Central 
Iranian plate and on the other hand are influenced by the movement of Ocean plate (Indian Ocean) towards the north in line with Makran coast which is subducted under a section of the Central Iranian continental plate (Lout Block). Since in Zagros and especially in the western part of it, the continent-continent collision is placed in more advanced stages, naturally the severity and frequency of its seismicity is low and vice versa its eastern part is more active in terms of seismicity. This activation is increased towards the interface between the Indian Ocean plate and the Arabian plate. The case study is located in the eastern part of Zagros. Earthquakes in Zagros have different magnitudes ( $M_{s}=5$ to 6.5). In Zagros fold belt there is no documentary evidence that indicates the occurrence of an earthquake larger than the 10 April event of Ghir and Karzin $\left(M_{s}=7.1\right)$ (Excluding strikeslip events of northwestern part of Zagros such as earthquake of Silakhor, 23 January 1909). Zagros earthquakes are not deeper than 30 kilometers and often occur in simple fold belt. Teleseismic modeling of body waves shows that the majority of large earthquakes are focused in the depths of 10 to 20 kilometers (under the sedimentary covers) which is estimated from stratigraphic or aeromagnetic data.

\subsection{Seismotectonics Survey of Behbahan}

Situation and characteristics of faults in a zone and characteristics of its earthquakes could represent seismotectonics situation of the desired zone. Based on previous studies, five divisions for states and seismotectonics zones are identified for this region [4].

1) Barbarian classification

Barbarian considered four fundamental seismotectonics areas for Iran [5]. According to these divisions Behbahan is located in Zagros zone.

\section{2) Norouzi classification}

Norouzi have divided 23 seismotectonics states that according to this classification Behbahan is located in 6th state, i.e. Zagros range, and incidentally, Zagros and Fars states have the minimum return period (the maximum frequency) in the case of small and medium earthquakes (up to 5.6 on the Richter scale) [5].

3) Seismotectonic group classification and zoning relative risk of earthquake in Iran

Based on zoning studies on relative risk of earthquake in Iran, of national physical planning studies in Iran by the Center of Urban Studies and Architecture of Iran, 10 zones are separated in Iran [5] that Khuzestan is one of these zones. Khuzestan (including cities of Khuzestan and Kohgiluyeh and Boyer Ahmad) from the viewpoint of tectonic is placed in subgroups of Zagros Fold-thrust and Zagros Foothills (Dezful embayment). The boundary between these two subgroups is mountain front flexural fault that leads to differentiation of Zagros fold-thrust from Zagros foothills and has caused massive earthquakes with its activities.

\section{4) Tehran Padir Consulting Engineers classification (1375)}

Tehran Padir Consulting Engineers have also divided Iran into seven major geological-tectonic units and some of these units have been seismotectonically divided into sub-units [5] and totally 20 units have been introduced and Behbahan is located in the $13^{\text {th }}$ zone. In this classification earthquake parameters are estimated based on earthquake in 1900 to early 1995 and historical earthquakes in 680 to 1889 AD.

5) Pourkermani and Asadi classification

In this classification, Iran is divided into 27 seismotectonics states based on earthquake of 1900 and 1992 [5] that Behbahan, Ahvaz and Khorramshahr are located in $8^{\text {th }}$ zone of Zagros (fold Zagros). The probability of earthquakes with high intensities in this zone is low, in other words this zone is a semi-active seismic zone. Geologically, this area includes the main part of simple fold belt. Thus it can be seen that based on all classifications, Behbahan is located in very seismically active zone.

\section{6) General seismicity of project area}

Case study is located in relative high risk zone based on the third edition of ISO 84-2800 of Building and Housing Research Center entitled seismic design building code, so the base acceleration of $0.3 \mathrm{~g}$ in the quasistatic calculations is recommended.

\section{Main Faults in Bahbahan Structure and Surrounding Areas}

In this section, along with gathering all existing data, faults in study area are surveyed and characteristics of the current recoveries are presented with a complete overview on the earlier works. Accurate and complete understanding of Quaternary faults in project area is the first step in the study of seismotectonics and earthquake faulting risk in the project area. Young fundamental faults with a length of more than 10 kilometers have been 
studied in the range of $100 \mathrm{~km}$ around the Behbahan structure. Young age and long length of these faults make them fundamental faults. The characteristics of more important identified and surveyed faults in this area are as follows:

Aghajari reverse fault: Aghajari reverse fault is a fault with the length of $140 \mathrm{~km}$ and NW-SE direction and dipping towards the northeast which is in line with the Aghajari anticline (Omidiyeh and Pazanan mountains) on the coastal plain at the opening of the Persian Gulf in Omidiyeh zone. Hanging wall of this fault is formed of Gachsaran, Aghajari and Mishan (in the northeast) formations and the coastal plain is formed of young Quaternary alluvium [6]. Satellite images and aerial surveys clearly show that Aghajari revers fault is the sharp boundary between mountains (in the northeast) and plain (in the southwest), and in addition to causing difference in elevation between mountain and plain, also increases the number of layers of mentioned formations. The elevation difference over 100 meters in Omidiyeh is caused by this fault activity. The minimum distance between Aghajari reverse fault and Behbahan is $35 \mathrm{~km}$. Magnitude of earthquake which may occur along the Aghajari reverse fault (with a length of $150 \mathrm{~km}$ ) assuming movement of $50 \%$ of the length of the fault in the future will be equal to $M_{s}=7.48$.

Ramhormoz reverse fault: Ramhormoz is a reverse fault with NW-SW direction and dipping towards the northeast. The fault has a length of about $100 \mathrm{~km}$ and is abducted on Aghajari, and Bakhtiari formations and Quaternary alluvium of Ramhormoz plain in line with the kerosene anticline with Gachsaran, Mishan and Aghajari formations (hanging wall). About $70 \mathrm{~km}$ of the length of Ramhormoz fault forms the boundary between the mountain and plain and is observed as a light line on satellite, aerial images and on the ground. This fault in addition to causing the elevation difference between mountains and plains also crosses over layers of formations mentioned above [6]. The minimum distance between Ramhormoz reverse fault and Behbahan is about $50 \mathrm{~km}$. Using existing equations, the magnitude of earthquake which may occur along the Ramhormoz reverse fault (with a length of $100 \mathrm{~km}$ ) assuming movement of $50 \%$ of the length of the fault in the future will be equal to $M_{s}$ $=7.32$.

Rag-e sefid reverse fault: Rag-e sefid fault is a reverse fault with NW-SW direction and dipping towards the northeast. The fault has a length of about $90 \mathrm{~km}$ and its northeastern part is bended and becomes north-south. The hanging wall of this fault consists of Mishan and Aghajari formations which are abducted on the coastal plain alluvium of opening of the Persian Gulf in the northern of Deilam port. Rag-e sefid fault forms the boundary between the mountain and plain and is observed as a light line on satellite, aerial images and on the ground. The minimum distance between Rag-e sefid reverse fault and Behbahan is equal to $55 \mathrm{~km}$. Using existing equations, the magnitude of earthquake which may occur along the Rag-e sefid reverse fault (with a length of $90 \mathrm{~km}$ ) assuming movement of $50 \%$ of the length of the fault in the future will be equal to $M_{s}=7.27$.

Behbahan reverse fault: This fault is located in $8 \mathrm{~km}$ north of Behbahan and $2 \mathrm{~km}$ north of Arjan and Mansoorieh. The direction of the fault is NW and is dipping towards northeast and has a length of about $80 \mathrm{~km}$. In line with this fault Gachsaran formation (hanging wall of the northeast) is abducted on the northern alluvium of Behbahan and Arjan (southwestern). Satellite images and aerial surveys show the fault as a straight line. In field study it was seen that Gachsaran formation layers near Behbahan fault dipping about $55^{\circ}$ towards the northeast. This dip suddenly increased to 80 degrees. What is clear is that a part of Behbahan plain subduction is due to activity of this fault. The minimum distance between Behbahan fault and Behbahan in about $5 \mathrm{~km}$. Using existing equations, the magnitude of earthquake which may occur along the Behbahan reverse fault (with a length of 80 $\mathrm{km}$ ) assuming movement of $50 \%$ of the length of the fault in the future will be equal to $M_{s}=7.22$.

Mishan fault: Mishan fault is located in $80 \mathrm{~km}$ of Behbahan with a direction of NW-NE and dipping towards $\mathrm{NE}$ and a length of $70 \mathrm{~km}$. The western part of Mishan fault in central Mishan zone is moved at the time of 2 July 1972 earthquake with a magnitude of $m_{b}=5.4$. The minimum distance between Mishan fault and Behbahan is about $80 \mathrm{~km}$. Using existing equations, the magnitude of earthquake which may occur along the Mishan fault (with a length of $70 \mathrm{~km}$ ) assuming movement of $50 \%$ of the length of the fault in the future will be equal to $M_{s}=$ 7.16 .

Arajan major fault: Arjan major fault is located in $10 \mathrm{~km}$ north of Behbahan, and $4 \mathrm{~km}$ north of Arjan parallel with Behbahan reverse fault. This fault direction is NW-SE. This fault is observed as a strength line between Bandi mountain in north (consist of Asmari limestone) and Gachsaran hills and Behbahan sunduction (in south) on satellite, aerial images. The fault is located in $2 \mathrm{~km}$ west of the opening of Maroon River, between Asmari and Gachsaran formations. Using existing equations, the magnitude of earthquake which may occur along the Arajan major fault (with a length of $60 \mathrm{~km}$ ) assuming movement of $50 \%$ of the length of the fault in 
the future will be equal to $M_{s}=7.09$.

Dogonbadan revers fault: Dogonbadan reverse fault is a fault with the length of $55 \mathrm{~km}$ and NW-SE direction and dipping towards the northeast which is located in $50 \mathrm{~km}$ north of Behbahan in north of Dogonbadan. Hanging wall in line with this fault is formed of Ashmari formation which is abducted on Dogonbadan plain alluvium [6]. The minimum distance between Dogonbadan reverse fault and Behbahan is about $50 \mathrm{~km}$. Using existing equations, the magnitude of earthquake which may occur along the Dogonbadan reverse fault (with a length of $55 \mathrm{~km}$ ) assuming movement of $50 \%$ of the length of the fault in the future will be equal to $M_{s}=7.05$.

Aneh reverse fault: Aneh reverse fault is a fault with the length of $55 \mathrm{~km}$ and NW-SE direction and dipping towards the northeast which is located in $40 \mathrm{~km}$ north of Behbahan. Ashmari formation is abducted on plain alluvium in line with this fault. The minimum distance between Aneh reverse fault and the north of Behbahan is about $40 \mathrm{~km}$. Using existing equations, the magnitude of earthquake which may occur along the Aneh reverse fault (with a length of $55 \mathrm{~km}$ ) assuming movement of $50 \%$ of the length of the fault in the future will be equal to $M_{s}=7.05$.

Basht reverse fault: Basht reverse fault is a fault with the length of $50 \mathrm{~km}$ and NW-SE direction and dipping towards the northeast which is located in $85 \mathrm{~km}$ north of Behbahan. Basht fault clearly crosses the southwest flank of Basht anticline and shows the boundary between mountain and plain and causes elevation difference. Despite Quaternary age of Basht reverse fault, no seismic data have been directly reached from it. The minimum distance between Basht reverse fault and the north of Behbahan is about $85 \mathrm{~km}$. Using existing equations, the magnitude of earthquake which may occur along the Basht reverse fault (with a length of $50 \mathrm{~km}$ ) assuming movement of $50 \%$ of the length of the fault in the future will be equal to $M_{s}=7.00$.

North Dehdasht reverse fault: This fault is a fault with the length of $45 \mathrm{~km}$ and NW-SE direction and dipping towards the northeast which is located in northeastern zone of Dehdasht and southwest of Black mountains. The minimum distance between this fault and Behbahan is about $35 \mathrm{~km}$. Using existing equations, the magnitude of earthquake which may occur along the Dehdasht reverse fault (with a length of $45 \mathrm{~km}$ ) assuming movement of $50 \%$ of the length of the fault in the future will be equal to $M_{s}=6.95$.

Arajan minor fault: At $3 \mathrm{~km}$ north of Arajan, between the major faults of Arajan in the north and Behbahan in the south, and Maroon River in the west, a short fault entitled Arjan minor fault can be seen among the hills of Gachsaran formation (in the southwest) and a small subduction zone (in the northwest). The minimum distance between this fault and Behbahan is about $4 \mathrm{~km}$. Using existing equations, the magnitude of earthquake which may occur along the Arajan minor fault (with a length of $8 \mathrm{~km}$ ) assuming movement of $50 \%$ of the length of the fault in the future will be equal to $M_{s}=6.15$.

Pazanan thrust fault: This fault passes the north and north-west region of Sardasht and its northwest southeast trend is in line with Zagros thrust and is in compliance with Zagros tectonic. Pazanan trust separates Ghale Dokhtar Mountain and the mountains of northern Sardasht from Neogene alluvial. In these anti-Klein, a large number of oil wells are extracting [6].

Dezful embayment thrust fault: This fault passes zone the north of the region and its northwest-southeast trend in perfect harmony with Zagros fold trend and is in compliance with the tectonic zone of Zagros. Dezful embayment trust separates great flat plains of southwestern Khuzestan which are known as Dezful embayment from Zagros fold- thrust zone.

Back-tilting in young alluvial terraces: In $9 \mathrm{~km}$ north-northeast of Behbahan, and $2 \mathrm{~km}$ west of the Maroon River, in the northern area of Arjan minor fault, great back tilting can be seen in sediments of alluvial terraces. At this point alluvial terraces rather than an initial dip towards the north have $20^{\circ}$ dip towards the north. This back tilting is caused by the movement of Arajan small fault and other minor fault in the north of this point. The fault is a thrust fault and has a shear $2 \mathrm{~m}$ zone. The young alluvial terraces back tilting and their shear is a sign of active area.

Banghestan anticline: A good section of Banghestan anticline is seen in the area. Anticline on the ground is limited with Sarvak limestone which its southern part is in line with the mountain front fault. Earthquake fountain associated with the Banghestan anticline at the ground is shown as part-fault. This part-fault will be considered in assessing the seismic risk [6].

\section{Mechanism Governing Behbahan Construction Faults and Surrounding Area}

The main well known faults in Behbahan zone and surrounding area are all important and fundamental faults 
and a large group of them are boundary of mountain and plain and topography making faults associated with the development and bending are anticlines. Accurate age and seismicity data of the zone faults and in general other faults of Iran is not available. mechanism of known main faults of Behbahan and surrounding zone all are reverse or have a major compressive component. It should be noted that reverse fault (compared with the strikeslip and stretching fault) has more energy (Sibson, 1974, 1975, 1977) its return period, in line with its trend is relatively longer, horizontal gravity acceleration in their length is more (Campbell, 1981) and can cause large and devastative earthquakes (Berberian, 1981).

\section{Conclusion}

Among the natural hazards, destructive earthquakes are the most common cause of casualties and financial losses. By increasing urbanization and population growth, the risk of earthquakes increases every moment and the result will be more destructive. Iran is located on Alps-Himalayas seismic belt and is under pressure of Arabian, India, Eurasia and Turkey tectonic plates. This country is one of the most earthquake-prone countries in the world and more than 70 percent of Iranian cities are seismically active. Khuzestan is one of the important provinces of the country that a part of this province has low seismicity risk due to locating in Saudi tectonic plate and another part, such as Behbahan has a high seismic risk. Seismicity of Behbahan is mainly related to the activities of existing faults. In this study the most important faults in the Behbahan zone that have high seismicity risk are as follows: Aghajari, Ramhormoz, Rag-e sefid, Behbahan, Mishan, major Arjan fault, Dogonbadan, Aneh, Basht, North Dehdasht, and minor Arjan fault. Due to frequent earthquakes in Behbahan and its multiple faults, this city has a high seismic potential and localization and construction in the city must be more accurate.

\section{References}

[1] Zaherman, S. (2009) Seismic Microzonation of Behbahan. Master Degree Thesis, Engineering Faculty, Islamic Azad University of Najafabad, Najafabad.

[2] Bazyar, M.H. and Zahermand, S. (2010) Behbahan Earthquake-Fault Risk Analysis. International Conference of Lightweight Construction and Earthquakes, 1-2 May 2010.

[3] (1985) Seismotectonics and Earthquake Risk Estimation of Maroon Dam. Khuzestan Water and Power Authority.

[4] Hatef Bazyar, M.H. Impact of Structural Parameters on the Changing Nature of Possible Earthquake in Yasouj.

[5] Seismotectonics Group and Earthquake Relative Risk Estimating Group (1997) Earthquake Relative Risk Zonation in Iran. Iranian Studies and Research Center of Urban Planning and Architecture.

[6] (1985) Barbarian, Faulting in Maroon Dam Zone (Behbahan). 